Revista Mídia e Cotidiano

ISSN: 2178-602X

Artigo Seção Temática

Volume 15, Número 2, maio/ago. de 2021

Submetido em: 21/02/2021

Aprovado em: 16/04/2021

\title{
Fotojornalismo e representações da educação: as narrativas sobre o contexto de precariedade no ensino remoto brasileiro
}

Photojournalism and the representation of education: narratives about the precarious conditions in the brazilian remote education

\section{Fotoperiodismo y representaciones de la educación: las narrativas sobre el contexto de precariedad en la enseñanza remota brasileña}

\author{
Carlos PERNISA JÚNIOR ${ }^{1}$ \\ Paulo Roberto Figueira LEAL ${ }^{2}$ \\ Monique Ferreira CAMPOS ${ }^{3}$
}

\begin{abstract}
Resumo
O presente artigo dedica-se a analisar as fotografias que circularam nos ambientes digitais dos jornais $O$ Globo e Folha de S.Paulo no ano de 2020 direcionadas para o tema da educação. Buscamos compreender como os veículos abordaram as condições de precariedade dos sujeitos educandos na construção das narrativas visuais sobre a falta de acesso à educação no período da pandemia. Trata-se de um estudo voltado para os elementos compositivos mobilizados nas fotografias de notícias sobre o ensino remoto no Brasil, nas significações da identidade e da diferença, utilizando-se da metodologia de análise de conteúdo. Para tanto, buscamos fundamentar a análise nas teorias construcionistas do jornalismo, culturalistas, da Fotografia-expressão e também nos estudos sobre a sociedade midiatizada.
\end{abstract}

Palavras-chave: Fotojornalismo. Midiatização. Educação. Representação social. Alterida.

\footnotetext{
${ }^{1}$ Professor titular da Faculdade de Comunicação da Universidade Federal de Juiz de Fora (UFJF) e professor permanente do Programa de Pós-Graduação em Comunicação da UFJF. Líder do Grupo de Pesquisa Laboratório de Mídia Digital. E-mail: carlos.pernisa@ufjf.edu.br. ORCID: 0000-0002-50030094.

2 Professor titular da Faculdade de Comunicação da Universidade Federal de Juiz de Fora (UFJF) e professor permanente do Programa de Pós-Graduação em Comunicação da UFJF. Líder do Grupo de Pesquisa Comunicação, Identidade e Cidadania. E-mail: pabeto.figueira@uol.com.br. ORCID: 00000002-9935-1614.

${ }^{3}$ Doutoranda pelo Programa de Pós-Graduação em Comunicação da Universidade Federal de Juiz de Fora (UFJF) na linha de pesquisa Mídias e Processos Sociais. Integrante do Grupo de Pesquisa Laboratório de Mídia Digital. E-mail: monique.campos@ufjf.br. ORCID: 0000-0003-4930-0947.
} 


\section{Abstract}

This paper intends to analyse the photographs that circulated in digital environments by $O$ Globo and Folha de S.Paulo newspapers during the year 2020 addressed to the theme of education. We seek to understand how those vehicles aproached the precarius conditions from which the students built visual narratives about the lack of access to education in the pandemic context. It is a study focused on the compositional aspects engaged in news photography about the remote education in Brazil, it is also focused in the identity and difference meanings. For this purpose, the content analysis has been used. Therefore, we seek to ground our analysis on constructionist journalism, culturalist, Photography-expression theories, and also in the studies on mediatized society.

Keywords: Photojournalism. Mediatization. Education. Social representation. Otherness.

\section{Resumen}

El presente artículo se dedica a analizar las fotografías que se han divulgado en los ambientes digitales de los periódicos O Globo y Folha de S.Paulo del año 2020 direccionadas al tema de la educación. Buscamos comprender como los vehículos han abordado las condiciones de precariedad de los estudiantes en la construcción de las narrativas visuales sobre la falta de acceso a la educación en el período de la pandemia. Se trata de un estudio volcado hacia los elementos compositivos movilizados en las imágenes periodísticas sobre la enseñanza remota en Brasil, en las significaciones de la identidad y de la diferencia, utilizándose de la metodología de análisis de contenido. Para tanto, buscamos fundamentar el análisis en las teorías construccionistas del periodismo, culturalistas, de la Fotografía-expresión y también en los estudios sobre la sociedad mediatizada.

Palabras clave: Fotoperiodismo, Mediatización, Educación, Representación social, Alteridad.

\section{Introdução}

A segunda quinzena do mês de março de 2020 foi marcada pela adoção do isolamento social em todo o país como medida para evitar a disseminação do novo coronavírus. Escolas e universidades suspenderam as aulas presenciais e foram obrigadas a encontrar alternativas para a educação na quarentena. Grande parte das instituições adotou o ensino remoto emergencial, de forma que atividades escolares e acadêmicas, bem como recreativas, foram desenvolvidas para disponibilização em plataformas online. Além das diversas dificuldades que envolvem a falta da socialização e das aulas presenciais, muitas crianças e jovens estão sendo amplamente afetados por várias carências: acesso às tecnologias digitais e à Internet necessárias ao ensino remoto; materiais impressos de apoio aos estudos em casa; ambientes que ofereçam condições 


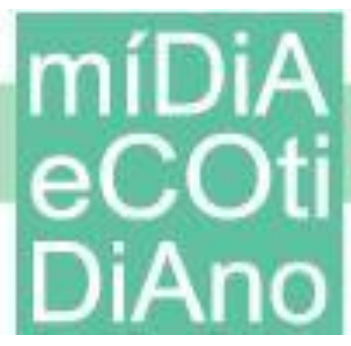

para estudar; acesso a uma alimentação apropriada; possibilidades econômicas para a permanência nos estudos; entre outras.

As questões que envolvem a desigualdade educacional no Brasil, entre elas a vulnerabilidade de estudantes e ausência de condições para a oferta e participação do ensino remoto, fazem parte da atual cobertura noticiosa. As fotografias jornalísticas trazem narrativas sobre diversos personagens que vivenciam as problemáticas educacionais, portanto sociais, da interrupção do ensino presencial. As imagens apresentam condições de precariedade, que conformam muitos retratos do ensino remoto no Brasil. No que diz respeito aos sujeitos representados nessas fotografias, evidencia-se a construção de um lugar da alteridade: aqueles que não estão incluídos nas demarcações das identidades estudantil e de educadores, portanto à margem dos processos educacionais no contexto de isolamento social.

Nesse sentido, o artigo busca analisar como as fotografias que circularam nos ambientes digitais dos jornais tradicionais brasileiros $O$ Globo e Folha de S.Paulo abordaram as vulnerabilidades sociais e situações de precariedade relacionadas ao não acesso ao ensino remoto emergencial, assim como a serviços básicos e apoio pedagógico. Realizamos um levantamento das reportagens que trouxeram esse tema por meio da fotografia, divulgadas entre os meses de março e novembro de 2020. Quais elementos compositivos foram mobilizados pelas fotografias para noticiar esses aspectos? Utilizamos a metodologia de análise de conteúdo para a coleta e posterior análise geral das fotografias, não nos detendo em aprofundamentos técnicos e estéticos das fotografias estudadas, uma vez que são muitas imagens inclusive compondo reportagens disponibilizadas em galerias.

Para tanto, consideramos os processos de significação da vida social, da identidade e da diferença no cenário midiatizado, em que a comunicação se faz estrutural na vida social e a mediação tecnológica base das práticas culturais. Para chegarmos a essa reflexão sobre o cenário contemporâneo, recorremos ao pensamento comunicacional fundamentado nas perspectivas construcionistas do jornalismo e também nas teorias fotográficas que consideram as imagens em circulação na imprensa formas de expressão simbólica e, portanto, fenômenos da representação. 


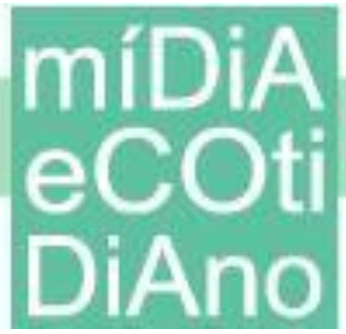

\section{Jornalismo e fotografia nas concepções sobre a realidade e a sociedade}

As teorias interacionistas adquiriram relevância nos estudos da comunicação com abordagens voltadas para os processos de significação, produção do conhecimento e ação social. Nesse contexto, as perspectivas sobre o conceito de realidade sempre foram importantes direcionadoras das teorias que tratam do jornalismo, uma vez que a atividade é uma forma particular de produção do conhecimento e está alicerçada nos acontecimentos do mundo, sendo assim vinculada ao "real" e "verídico".

Berger e Luckmann (2007) estabeleceram o argumento de que a realidade nos é dada como algo certo, externo às atividades humanas, porém ela é socialmente construída através de processos de interação social, mediados por linguagens. O conhecimento é socialmente estabelecido como realidade, princípio que norteia reflexões sobre as condições de uma cultura midiática, noticiosa, nas dinâmicas institucionais e das interações cotidianas.

Ao relacionar teorias construcionistas e jornalismo, Alsina (2009) destaca que a concepção da realidade pode ser vista também como produto da mídia, em processos de institucionalização, circulação e reconhecimento. Os jornalistas têm um papel socialmente legitimado para construir a realidade como pública e socialmente relevante, o que se dá no interior dos sistemas simbólicos da mídia. O papel atribuído ao jornalismo, o de "fazer saber", juntamente ao vínculo com a ideia de real, conforma a credibilidade dada à informação jornalística.

A mídia noticiosa, portanto, pode ser entendida como relevante instância discursiva e mediadora na vida social, compondo processos simbólicos em que acontece o jogo das representações sociais. Os sistemas midiáticos envolvem elementos de controle e circulação de interpretações, sendo o jornalismo um importante ator nos processos de socialização já que possui sua própria ritualística.

No que se refere à fotografia de imprensa, a aproximação do pensamento de que a realidade é objetiva e exterior às atividades interativas da humanidade foi bastante empregada ao longo da história. A presença da fotografia nos noticiários, desde a constituição de um jornalismo visual, sempre foi associada à ideia de realidade. Na mídia impressa em geral, a fotografia se estabeleceu vinculada aos valores informativos da atualidade e relevância social, sendo utilizada enquanto critério de validação. A fotografia 


\section{míiA
eCOti
DiAno}

foi aceita enquanto prova definitiva e testemunho da verdade, o que se configurou como status de credibilidade (KOSSOY, 2009). Fotografia, jornalismo e objetividade estabeleceram uma relação intrínseca na sociedade moderna.

Conforme Buitoni (2011), a objetividade foi utilizada enquanto legitimação da fotografia no jornalismo, um dos primeiros postulados da notícia visual. O realismo para o pensamento moderno aparece de maneira muito mais forte quando o produto midiático decorre de uma matriz fotográfica, sendo que a fotografia se beneficia de uma transferência de realidade da coisa para a sua reprodução, seguindo as ideias apresentadas pela autora. $\mathrm{O}$ amadurecimento da reportagem fotográfica na imprensa brasileira se deu como "índice de modernidade" e, assim, o repórter fotográfico assumiu o papel de "testemunha ocular da história". A fotografia era tida como documento fiel da realidade, ganhando o estatuto de idoneidade, "um documento de primeira mão, bruto, quente, da vida ali impressa" (MONTEIRO, 2000, p. 49).

Entretanto, estudos da comunicação e sobre a fotografia, especificamente, com forte viés culturalista, pós-estruturalista e interacionista, subverteram essa natureza objetiva das imagens e buscaram enfatizar seus traços simbólicos. Arlindo Machado (1984) traz, em uma de suas obras, aspectos desse movimento, uma vez que destaca as questões que unem imagens técnicas e ideologia; os enquadramentos, interesses de enunciação e as transformações do real que se dão por meio da fotografia. O realismo é tido como atributo fundamental da própria maneira de se criar e perpetuar imagens. As câmeras constroem suas próprias configurações simbólicas, fabricam "simulacros", assim, representações (MACHADO, 1984, p. 11).

O reconhecimento da atividade jornalística enquanto um sistema simbólico, uma instância com funcionamento interno específico ou "campo social” (BOURDIEU, 1989), evidencia a perspectiva construcionista da comunicação e o entendimento de um "real" relacional, ligado ao conceito de representações e, assim, aos modos de ver e de pensar o mundo. Os campos sociais - como o jornalismo e seus conjuntos de símbolos - são estruturas da sociedade que orientam as práticas e representações cotidianamente mobilizadas pelos agentes sociais. Seguindo esses preceitos, as teorias do jornalismo e os estudos sobre as imagens apontam a fotografia enquanto dispositivo cultural, um 


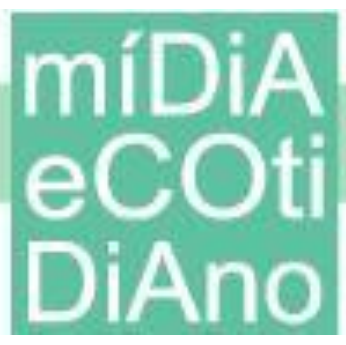

procedimento técnico-expressivo determinante do conteúdo visual da imprensa e que traz toda uma potencialidade narrativa (BUITONI, 2011, p. 58).

Essa reorientação do pensamento comunicacional estabeleceu bases para o entendimento do fotojornalismo na formação de imaginários sociais, na construção de sentidos sobre a sociedade e geração de identidades e diferenças. "A ordem simbólica nos apresenta aquilo a ser visto, experimentado, vivido: tanto os modos quanto as existências. O resto é silêncio" (GOMES, 2008, p. 26). O visual passou a ser teorizado enquanto parte fundamental da representação do "outro". O fotojornalismo trouxe definições dos acontecimentos do âmbito do "ver", do "espantar-se", do "comover-se" e do "ser instruído para", no contexto das representações sociais. Tais características configuraram os usos da fotografia e as principais distinções dentro da linguagem fotojornalística: o caráter noticioso, o documental e o ilustrativo. Essa ordem simbólica apresenta cotidianamente operações de significação e dessa forma, seguindo o pensamento de Silva (2000, p. 91), os sistemas de representação dão suporte e sustentação às identidades e diferenças.

\section{O fotojornalismo na condição comunicacional contemporânea}

A partir do entendimento de que o campo do jornalismo constitui-se enquanto práticas de significação, representação social e de organização da sociedade em identidades e diferenças, os olhares sobre a expansão da mídia na vida social contemporânea destacam as transformações que se dão em todos esses níveis. Atualmente vivenciamos uma condição comunicacional de midiatização intensificada da cultura e da sociedade, o que diz respeito às transformações das interações sociais e relações entre os vários atores sociais, incluindo os indivíduos e as organizações (HJARVARD, 2014). Dessa maneira, a midiatização diz respeito tanto aos domínios da mídia quanto às estruturas sociais, em um desenvolvimento bilateral. "A mídia denota os processos pelos quais a cultura e a sociedade tornam-se cada vez mais dependentes dos meios de comunicação e sua lógica como mídia integra-se em práticas culturais e sociais em vários níveis" (HJARVARD, 2014, p. 26).

A comunicação está fortemente presente na vida cotidiana e, nesse quadro, a mediação tecnológica passa a ser estrutural na sociedade. Conforme Barbero (2006), a 


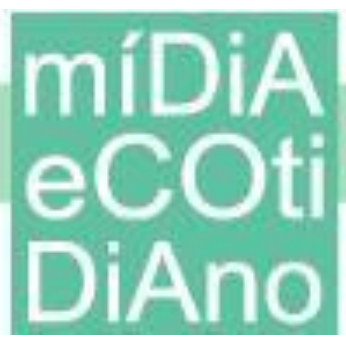

revolução das tecnicidades transforma radicalmente o lugar da cultura em nossas sociedades, de forma que "a tecnologia remete, hoje, não a alguns aparelhos, mas, sim, a novos modos de percepção e de linguagem, a novas sensibilidades e escritas" (BARBERO, 2006, p. 54). Trata-se de uma cultura mediada por dispositivos digitais que emergem a partir dos avanços da computação e Internet. Ao mesmo tempo, estão em convergência com os meios eletroeletrônicos que caracterizaram a comunicação de massa no século XX, compondo uma cultura híbrida e complexa. Para Sodré (2008), a vida social expandida pelas tecnologias determina o bios midiático, em que a virtualização das instâncias da vida social implica uma nova dimensão da realidade, novas categorias de espaço, tempo e formas de conhecer o mundo.

No que tange à relação histórica entre jornalismo e fotografia, o processo social da midiatização evidencia uma mudança de lógicas incluídas nas questões relacionadas ao suporte - do papel ao digital -, nas práticas profissionais e condições do jornalismo visual. Ao mesmo tempo, as transformações estão presentes nas dinâmicas das sociabilidades, nas interações estabelecidas com as fotografias de imprensa e construções de sentidos. A condição comunicacional contemporânea, em que se configura o jornalismo digital, reforça a fotografia desvinculada dos padrões de objetividade e valorizada pela força narrativa com que apresenta o acontecimento. Os estudos atuais sobre a fotografia consideram a crise das concepções de sua essência enquanto documento e as profundas mudanças que a levaram para o regime da expressividade (ROUILLÉ, 2009). As reflexões se apoiam nos conceitos sobre traços, rastros e contiguidade entre imagem e seu referente, o que demonstra a vulnerabilidade fotográfica, sobretudo no cenário complexo das produções em meios digitais.

Em se tratando da sociedade midiatizada, a fotografia tem como característica o alcance, a circulação por diversos meios e plataformas, sendo presença marcante na construção do mundo simbólico. Produções concebidas diretamente na Web - os veículos "nativos digitais" - possibilitam novas narrativas do fato jornalístico (MUNHOZ, 2007) e, desse modo, apresentações do conteúdo fotojornalístico em caráter hipermidiático e convergente. As imagens compõem notícias bem como interfaces e mapas de navegação em grandes reportagens multimídia, além das coberturas em 360 graus. Movimentos significativos foram os dos fluxos das fotografias jornalísticas para as redes sociais e 


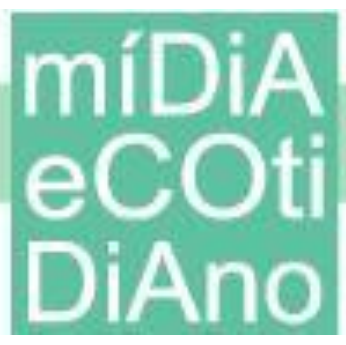

aplicativos de mensagens. Outro processo marcante é a produção noticiosa para tecnologias móveis, como smartphones e tablets, configurando práticas de mobilidade física e informacional (SILVA, 2015), além do que ficou conhecido como jornalismo participativo ou cidadão. "A esfera pública da mídia proporciona um espaço de experiência compartilhada que, em certa medida, compensa a diferenciação que caracteriza a maioria dos domínios sociais” (HJARVARD, 2014, p. 31).

A circulação das imagens em ambiente midiatizado constitui cenários culturais diversos, ao considerarmos o acesso, as apropriações e os usos sociais da mídia. Há uma “entrada experimental de participantes sociais nas práticas e processos antes restritos à indústria cultural” (BRAGA, 2012, p. 34), compondo uma espécie de convivência entre circuitos de informação da mídia tradicional e os circuitos alternativos. Ao mesmo tempo, um grande oligopólio gerencia fluxos de dados e a circulação de informações no contexto da sociedade midiatizada.

Na visão de Kellner (2001), a cultura veiculada pela mídia fornece o material que cria as identidades pelas quais os indivíduos se inserem nas sociedades tecnocapitalistas contemporâneas, produzindo uma nova forma de cultura global. A cultura da mídia e a de consumo andam de mãos dadas, ditando contornos entre indústria cultural e a vivência social. Os meios de comunicação produzem representações que tentam induzir anuências, ideologias, recursos de produção de significados e, assim, orientações de identidades (KELLNER, 2001, p. 211), da mesma forma que se transformaram no lugar das resistências e lutas.

O processo social da midiatização está implicado nas formas expandidas de construção do acontecimento, das identidades e também das diferenças. Nesse sentido, as fotografias tornam-se parte desses espaços de visibilidade - ou mesmo invisibilidade - e de referenciais para as experiências de alteridade. As narrativas sobre as identidades envolvem uma reconstrução conjunta, uma co-produção, porém em variadas situações de conflito e rupturas cada vez mais inseridas nos circuitos comunicacionais. "Uma teoria das identidades e da cidadania deve levar em conta os modos diversos com que estas se recompõem nos desiguais circuitos de produção, comunicação e apropriação da cultura" (CANCLINI, 1999, p. 173). 
A cobertura fotojornalística sobre o ensino remoto no Brasil: os discurcursos visuais dos jornais Folha de S.Paulo e $O$ Globo sobre a precariedade e a alteridade

A partir das implicações expostas nos itens anteriores, direcionamos nossos olhares para as relações entre os campos jornalístico e educacional, mais especificamente para a atividade fotojornalística e como essa tem evidenciado as temáticas e aspectos da educação, considerando os dispositivos de mídia digital onde se inscreve. No contexto atual, de isolamento social em função da pandemia de covid-19, buscamos analisar como a educação se inseriu no debate público pela via midiática, especificamente nas redes digitais de dois jornais tradicionais brasileiros: Folha de S. Paulo ${ }^{4}$ e $O$ Globo $^{5}$. Quais significados foram dados às situações de precariedade relacionadas ao ensino remoto emergencial no país a partir das fotografias? Referimo-nos às questões sociais que envolvem a falta de acesso às tecnologias digitais para os processos educacionais como um todo, assim como as desigualdades nos contextos de escolas e universidades. As fotografias apresentam sujeitos - educadores e educandos - oferecendo marcas identitárias e de alteridade. De que forma as mazelas educacionais entraram no cenário de circulação de imagens pelas plataformas digitais desses dois jornais?

Partimos de uma pesquisa exploratória nos portais da Folha e do $O$ Globo por notícias e reportagens que abordaram as problemáticas da falta de acesso à educação remota durante a pandemia, desse modo, os contextos de precariedade e vulnerabilidade social refletidas na pauta educacional. Selecionamos as matérias que trouxeram fotografias, as quais fazem parte do levantamento apresentado no Anexo ${ }^{6}$. A pesquisa envolveu os meses entre março e novembro de 2020, com início nos anúncios do fechamento das escolas brasileiras. Nesse estudo, lançamos nossos olhares para os elementos compositivos das fotografias mobilizados para a narrativa jornalística, com o foco nas escolhas de delimitação dos fatos e personagens, bem como nas marcas ideológicas (MACHADO, 1984). Buscamos, portanto, uma análise geral das mensagens

\footnotetext{
${ }^{4}$ Portal de notícias do jornal Folha de S.Paulo: https://www.folha.uol.com.br/.

${ }^{5}$ Portal de notícias do jornal $O$ Globo: https://oglobo.globo.com/.

${ }^{6}$ Os veículos Folha de $S$. Paulo e $O$ Globo exigem login de assinante para o acesso a muitas das reportagens que fazem parte do levantamento feito para este artigo (Anexo).
} 


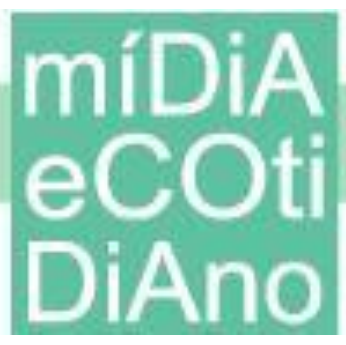

visuais, de modo a aproximá-las das formas utilizadas para a representação do contexto e da alteridade.

A metodologia de análise de conteúdo foi utilizada para a exploração do material coletado, categorização dos elementos visuais e análise das narrativas fotográficas produzidas pelos dois veículos estudados. Laurence Bardin define análise de conteúdo como o "conjunto de técnicas de análise de comunicações que utiliza procedimentos sistemáticos e objetivos de descrição do conteúdo das mensagens" (2008, p. 40). Nesta perspectiva, demanda-se que o procedimento de análise efetive o desdobramento das mensagens em suas partes constitutivas basilares - normalmente por meio da classificação em categorias, que podem ser previamente elencadas ou surgirem após a verificação de recorrências presentes no material analisado (caso deste trabalho).

A autora francesa sustenta que os procedimentos associados ao método baseiamse tanto em técnicas quantitativas quanto qualitativas. Busca-se, nesta tradição, construir indicadores que permitam a produção de inferências sustentadas pelas evidências. As fases costumam ser três: (a) pré-análise do material coletado; (b) exploração do material; (c) tratamento dos resultados obtidos e interpretação.

No presente artigo efetiva-se, portanto, uma análise de conteúdo dos materiais fotográficos publicados nos portais Folha de S. Paulo e $O$ Globo, no ano de 2020, direcionados ao tema da educação. A partir de análise exploratória do corpus, pretendese identificar padrões narrativos recorrentes no material, tendo como pano de fundo o binômio conceitual identidade-alteridade.

O ambiente doméstico é representado em grande parte das fotografias pesquisadas, não somente pela referência ao ensino remoto em situação de quarentena os traços do real -, mas também na adoção de uma ordem visual que mobiliza elementos compositivos para a representação do estado de precariedade. As narrativas visuais das situações de carência completas, ou de superação de desafios para tornar o lar um ambiente de ensino, convocam imaginários, lidam com clichês, ou seja, buscam vários elementos preexistentes que aproximam as reportagens da fotografia-expressão (ROUILLÉ, 2009). Sob esses regimes de escrita fotográfica, os traços de alteridade aparecem dentro do que se configura como desigualdades sociais, problemáticas da 


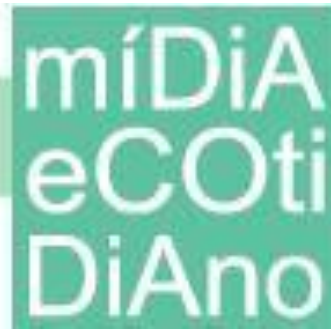

educação pública e, especificamente, as carências que são utilizadas para traduzir a educação remota no Brasil dentro dos espaços periféricos.

A sequência de fotografias de Marlene Bergamo/Folhapress demonstra muitas relações entre identidade e diferença e o ambiente doméstico enquanto lugar das significações da precariedade. Essas imagens, que compõem o ensaio "Aulas à distância durante a pandemia expõem desigualdades na educação", também foram utilizadas em outras sete reportagens da Folha, recebendo transformações de sentidos no curso da circulação noticiosa do jornal nas redes digitais. Nessas fotografias, personagens figuram situações outras que não as do momento de estudos, enfatizando a situação de ausência total de condições para o ensino remoto. Dentro da narrativa visual, elementos associam a precariedade com a moradia na periferia: cômodos inacabados, paredes descascadas, ambientes pouco iluminados, escadões de acesso às casas e becos. A reportagem traz, como última fotografia, a comparação com o quarto de uma jovem, aluna de escola particular, conduzindo suas atividades remotas em um ambiente espaçoso, onde há prateleiras de livros e um macbook em destaque.

Figura 1 - Fotorreportagem da Folha Online de 8 de maio de 2020

III 4/6 Aulas à distância durante a pandemia expōem desigualdades na educação

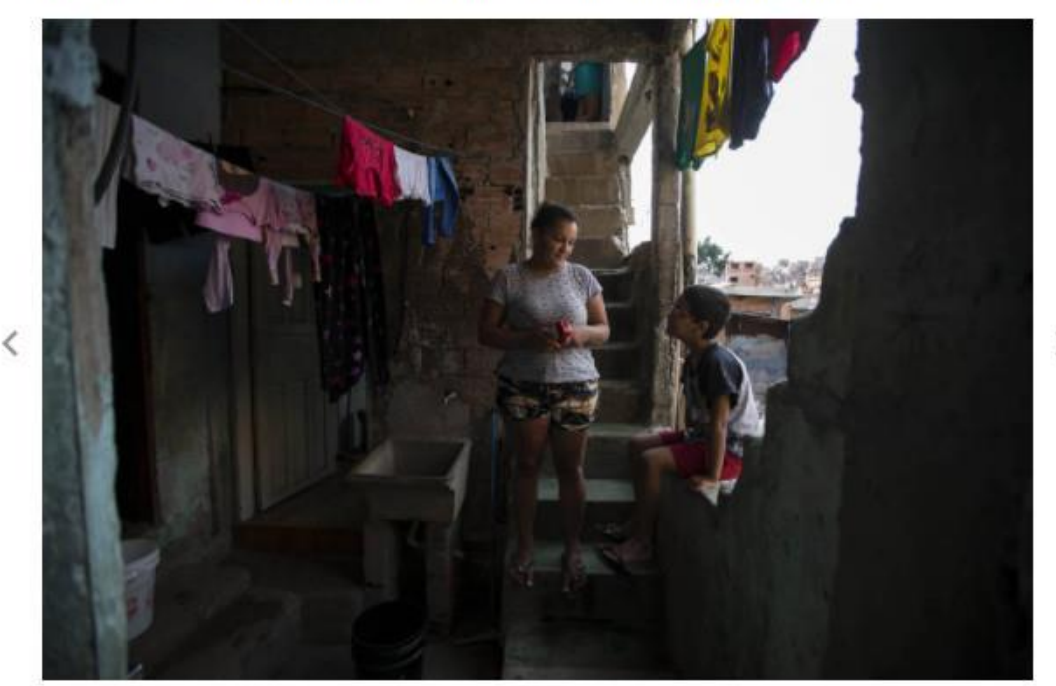

Jéssica Laurindo teme que o filho José Leandro Melo, 8 , esqueça o que aprendeu, já que não fez nenhuma atividade escolar desde que as aulas foram suspensas Marlene Bergamo/Folhapress

Fonte: Reprodução. 


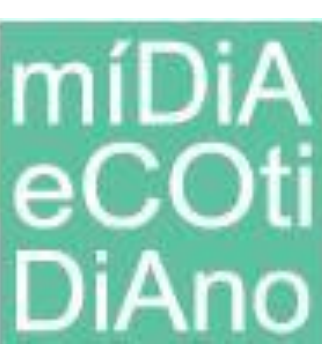

Figura 2 - Fotorreportagem da Folha Online de 8 de maio de 2020

:\# 6/6 Aulas à distância durante a pandemia expōem desigualdades na educação

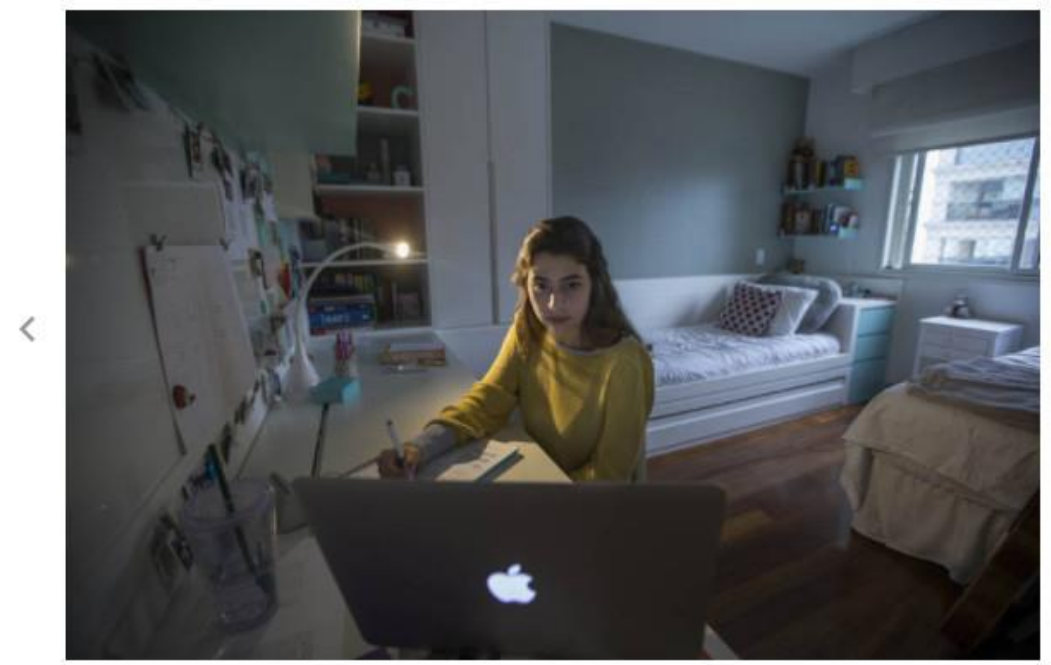

Há realidades diferentes, porém; Carolina Bertoletti, aluna do colégio particular Porto Seguro, mantém a grade curricular Marlene Bergamo/Folhapress

Fonte: Reprodução.

A precariedade do ambiente doméstico enquanto assunto condutor da narrativa sobre as desigualdades educacionais também é evidenciada pelos elementos compositivos das imagens de "Censo Escolar mostra que escolas públicas não têm equipamentos, nem práticas de educação digital" e "Maioria dos alunos que moram em favelas no país ficou sem estudar na pandemia", do jornal $O$ Globo. Nesses dois casos, os personagens posam para as fotografias que trazem, como molduras, elementos significativos da precariedade estrutural dos lares. Na porta de suas casas, as pessoas são retratadas com inscrições em uma linguagem que traduz o distanciamento social e tecnológico, índices de uma educação que não acontece. 


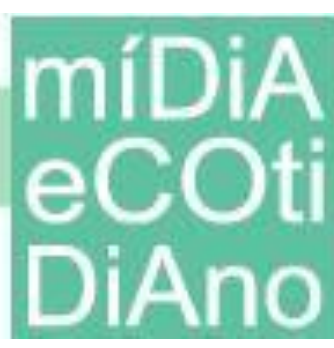

\section{PPGMC}

uff

Figura 3 - Da reportagem "Censo Escolar mostra que escolas públicas não têm equipamentos, nem práticas de educação digital” de 5/07/20

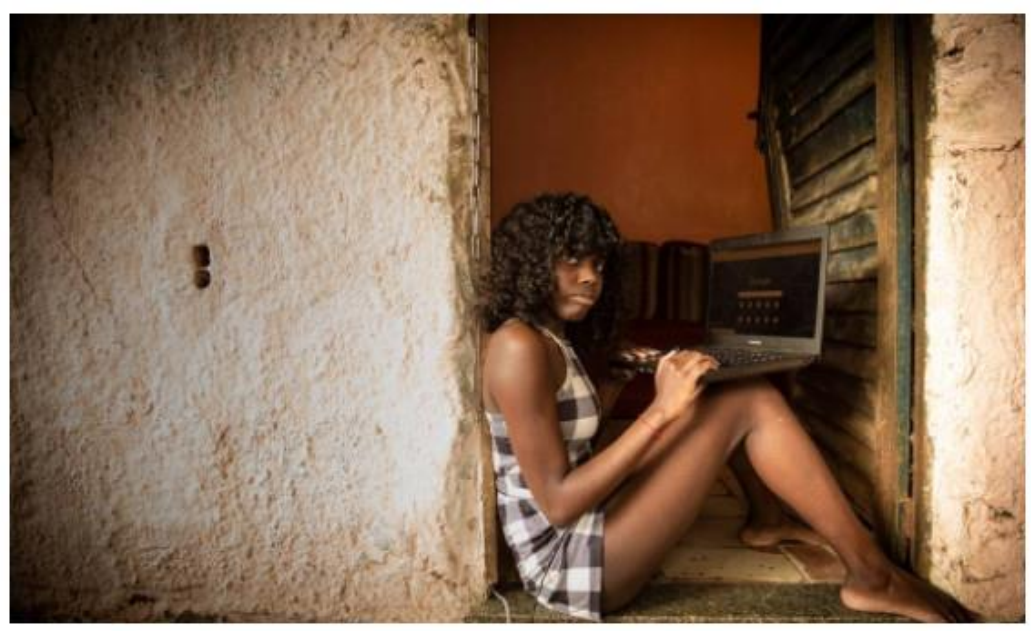

Tem computador, mas sem internet: moradora de Magé, Milene do Nascimento, de 16 anos, ficou dois meses sem estudar Foto: Roberto Moreyra / Agência O Globo

Fonte: Reprodução.

Figura 4 - Da reportagem "Maioria dos alunos que moram em favelas no país ficou sem estudar na pandemia" de 9/11/20

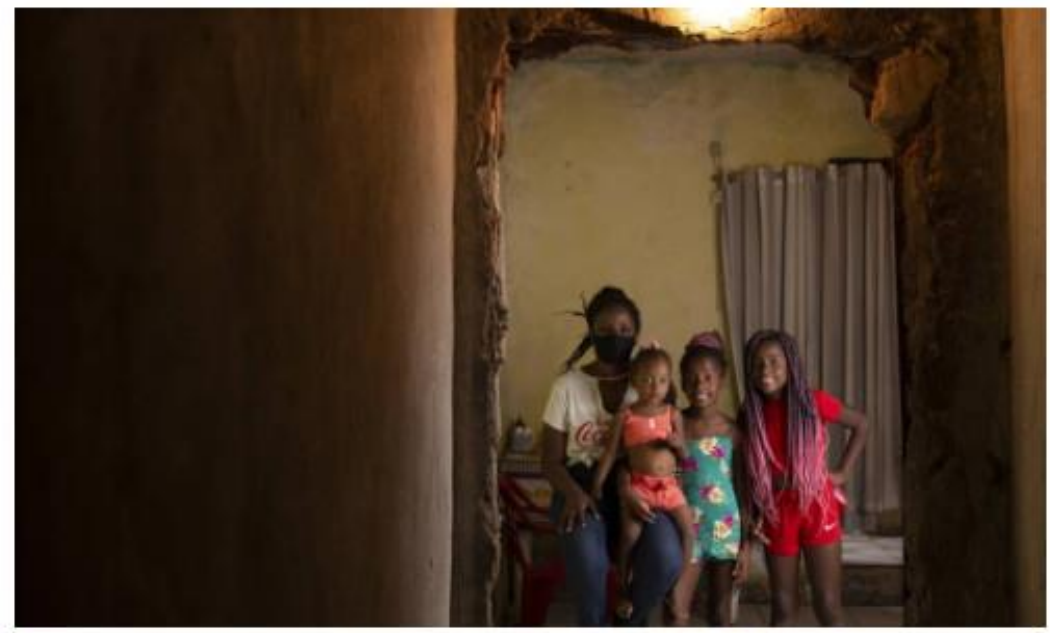

Suellen Pires, de 28 anos, vive com as três filhas na Vila Kennedy, Zona Oeste do Rio Foto: Gabriel Monteiro / Agência O Globo

Fonte: Reprodução.

Percebe-se ainda como a apresentação dos olhares dos personagens evidenciam as relações simbólicas definidas pelas reportagens. Os olhares para a câmera dos sujeitos fotografados em "Aulas à distância durante a pandemia expõem desigualdades na educação" e em "Alunos da escola pública de SP têm problemas no ensino a distância" 


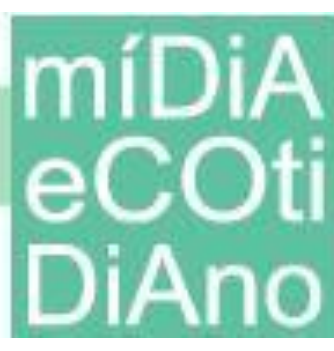

demonstram a imersão em uma situação de precariedade, de modo que as inscrições na narrativa trazem um silenciamento daqueles atores sociais. Há um apelo descritivo e ao mesmo tempo há o encontro com o outro - a câmera, a fotógrafa e todos aqueles que veem a fotografia - através da composição escolhida. As muitas fotografias posadas demonstram ainda mais o poder definidor dos significados por parte do jornalismo, sobretudo por conta da imagem se distanciar da linguagem do instante (SOUSA, 2002) com mais evidência nessas escolhas.

Não vemos as personagens em diálogo, em uma articulação discursiva, conduzindo as significações da precariedade nas fotografias - mesmo sabendo que o ato da fotografia jornalística acaba sendo alterado pelas dinâmicas do isolamento social. A maioria das fotos traz as personagens em performances do cotidiano em quarentena na casa, em serviços domésticos, demonstrando as escolhas fotojornalísticas para a abordagem das problemáticas da educação. O lar contextualiza toda a cena que envolve os personagens. Há um forte caráter descritivo nas imagens, que colocam essas pessoas no lugar da diferença, do que é conflituoso, daquilo que carece de resistência, mas recebeu aparências de sofrimento e incertezas. As fotografias de Márcia Foletto/Agência O Globo, em “'Há crianças passando fome': Estados e prefeituras deixam sete milhões sem merenda", "Estudantes de pelo menos 10 estados deixaram de receber alimentação escolar" e de Gabriel Monteiro/Agência O Globo, em "Maioria dos alunos que moram em favelas no país ficou sem estudar na pandemia", também demonstram como o jornalismo constrói as narrativas sobre a precariedade a partir dos olhares para a câmera em alguns momentos e dos olhares voltados para uma direção incerta, em outros. 


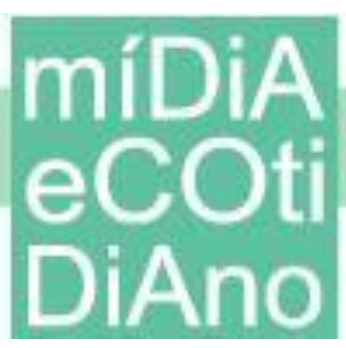

\section{PPGMC}

\section{uff}

Figura 5 - Fotorreportagem da Folha Online de 8/05/20

:\# 5/6 Aulas à distância durante a pandemia expōem desigualdades na educação

[I]

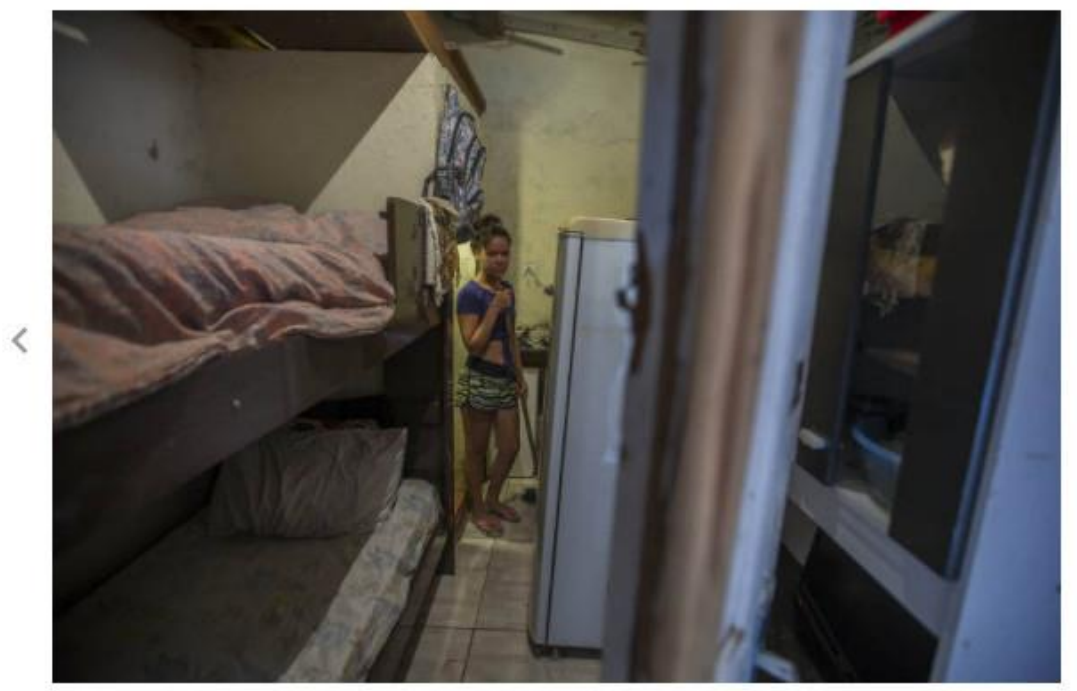

Sem saber que estăo sendo feitas aulas a distância na rede estadual de ensino, Ana Beatriz da Silva, 16 está desde o inicio da pandemia sem estudar Marlene Bergamo/Folhapress

$<$

Fonte: Reprodução.

Figura 6 - Da reportagem "'Há crianças passando fome': Estados e prefeituras deixam sete milhões sem merenda de 17/05/20

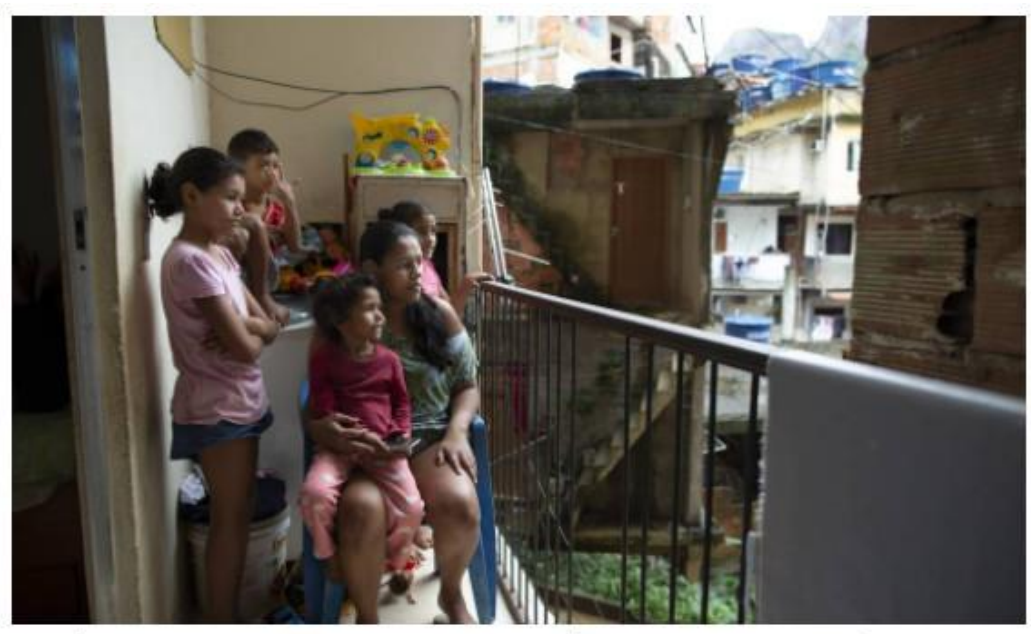

Ana Cláudia de Oliveira com os quatro filhos: moradores do Portão Vermelho, na Rocinha Foto: Márcia Foletto / Agência O Globo

Fonte: Reprodução.

A forma de apresentar as fotografias adotada pela Folha de S.Paulo em seu website é em galerias, séries de imagens que se voltam mais para as características de fotorreportagens. Percebe-se ainda um viés que dialoga com o ensaio e com aspectos 


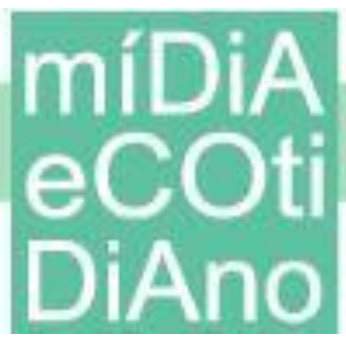

documentais, o que atua diretamente na mobilização de significados para a construção da realidade educacional da carência. Já o jornal $O$ Globo trabalha mais com fotografias que buscam resumir o acontecimento em uma imagem. $\mathrm{O}$ jornal também recorreu às imagens ilustrativas em suas reportagens, principalmente nas que trouxeram dados estatísticos sobre a desigualdade educacional brasileira. O veículo utilizou selfies enviadas por jovens entrevistadas em "Sem estrutura em casa, estudantes lutam para se preparar para o Enem 2020”, o que demonstra as condições de impedimento de produções fotográficas devido ao isolamento social.

Os personagens narram a falta de recursos para o ensino remoto, o uso de materiais impressos como alternativa para não pararem de estudar e a falta de espaço em casa para as atividades escolares. Esses aspectos estão presentes nas fotorreportagens "Na periferia de SP, mães tentam driblar falta de material para ensino a distância", "Ensino a distância em SP começa com dúvidas de pais e alunos", "Alunos da escola pública de SP têm problemas no ensino a distância", da Folha, e em "Sem estrutura em casa, estudantes lutam para se preparar para o Enem 2020", do O Globo. As matérias também trouxeram fotografias dos espaços escolares fechados e vazios, como em "Pandemia: 7,6 milhões de estudantes não tiveram aula em agosto, aponta IBGE”.

As relações de precariedade também estiveram presentes nas imagens que narram o uso compartilhado de um celular para as aulas remotas. As fotografias de Rubens Cavallari e Ronny Santos/Folhapress em "Alunos da escola pública de SP têm problemas no ensino a distância" apresentam essa questão juntamente com a ambientação de lares em que há cômodos apertados ou mesmo a disposição de móveis e eletrodomésticos variados no mesmo ambiente, caracterizando a falta de espaço. $\mathrm{O}$ uso do celular ainda demonstra a limitação de acesso à Internet, devido aos pacotes de dados, problema contemporâneo da ausência de políticas públicas de comunicação digital. A inscrição das personagens nessas relações de identidade e alteridade, por meio dos elementos visuais que convocam os significados da pobreza, destacam todo um referencial do habitar a periferia brasileira e do "não existir" em uma cultura digital. Trazem, assim, elementos da precariedade material como um todo. 
Figura 7 - Fotorreportagem da Folha Online de 16/08/20

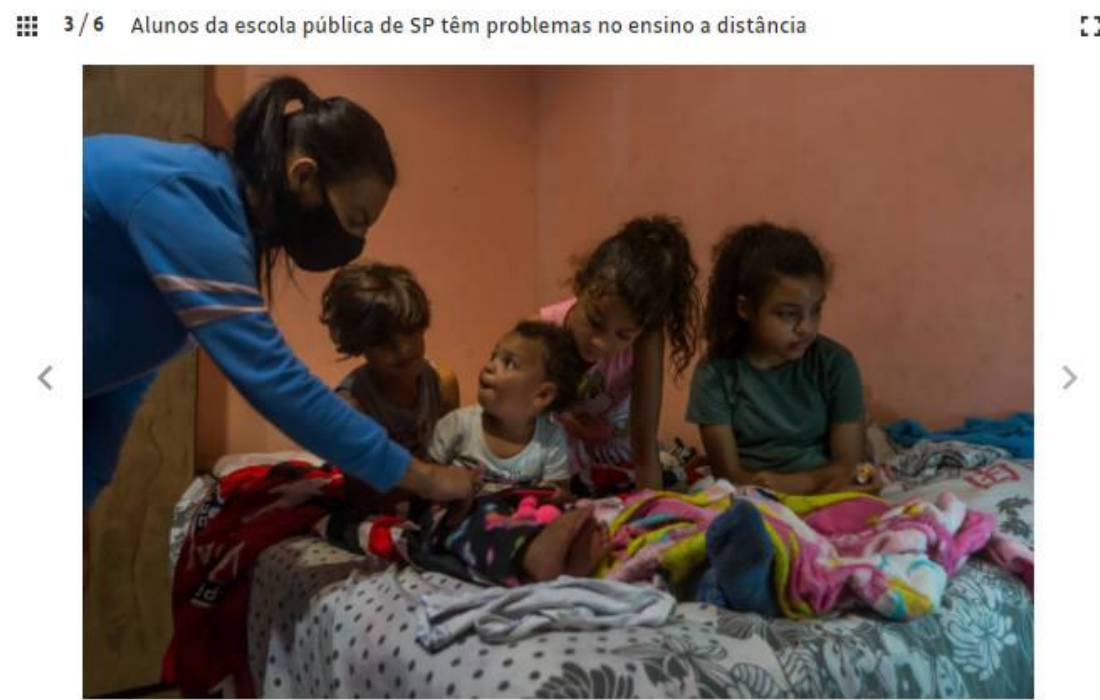

A vendedora, Rita de Cássia, 35 anos, tem 4 filhos: um está na creche e os outros três, em escola Estadual; há somente um celular para fazer as atividades da escola deles Ronny Santos/Folhapress $<$

Fonte: Reprodução.

As fotografias retratam ainda a precariedade alimentar de crianças e jovens que estão sem receber a merenda escolar. $\mathrm{O}$ assunto foi pautado por meio das referências ao ambiente doméstico, mais uma vez o mais exposto nas matérias “'Há crianças passando fome': Estados e prefeituras deixam sete milhões sem merenda" e "Estudantes de pelo menos 10 estados deixaram de receber alimentação escolar". Em "Escolas precisam de álcool em gel contra Covid-19, mas 10 mil das públicas não têm nem água limpa”, o jornal $O$ Globo ressaltou a precariedade estrutural da escola que não tem água encanada no momento em que os protocolos de biossegurança se fizeram essenciais. A fotografia destaca o poço utilizado para abastecer a escola, compondo a página e fazendo associações aos dados de várias outras comunidades que não têm acesso adequado à água potável.

Ao analisarmos a cobertura fotojornalística desses dois jornais tradicionais, percebemos as características da construção do acontecimento em forma de notícia (ALSINA, 2009). Situações de precariedade existentes no contexto social ganham caráter de excepcionalidade, crise/anormalidade e novos desenhos de exercício do poder sob o assunto "pandemia". Assim, são mobilizadas abordagens sobre a educação que levam o acontecimento a ganhar visibilidade com outras relações de sentido, nesse caso, de acordo 


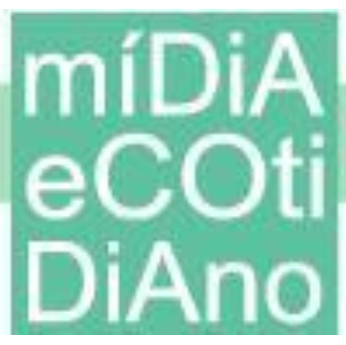

com as questões da saúde coletiva. Os dilemas educacionais das famílias empobrecidas ganham evidência e o jornalismo (re)organiza e (re)significa o cotidiano de precariedade. Conforme Sousa (2002, p. 17), as narrativas convencionais no fotojornalismo contribuem para que determinados acontecimentos sejam vistos como socialmente relevantes, em detrimento de outros. Em consequência, são promovidos à categoria de fotonotícias.

As abordagens culturalistas são cruciais para entendermos os elementos de (in)visibilidade midiática desse sujeito "outro" e das condições educacionais da vida na periferia. Ao ganhar relevância nos noticiários em mídia digital, numa condição de circulação de narrativas fotográficas em escalas ampliadas, as questões referentes às vulnerabilidades sociais entram em uma situação de organização simbólica, que se reverte em realizações de experiências de alteridade, mobilizações de percepções e referenciais. Percebe-se que a fotografia torna-se mais presente no noticiário educacional quando a pauta se direciona aos problemas sociais relacionados à falta do ensino remoto, sobretudo para estudantes de escolas públicas. O “fazer saber” jornalístico confere valorização às narrações sobre a desigualdade na educação, algumas com maiores - outras menores engajamentos para transformações da realidade. Os elementos compositivos fotográficos configuram importantes focos de atenção que, conforme Sousa (2002, p. 85), são um "fenômeno social".

Outra imagem que ganha relevância nas abordagens sobre a falta do ensino remoto é a das mães: cuidadoras, administradoras dos lares e as responsáveis pelo acompanhamento da vida escolar dos filhos. Praticamente todas as reportagens selecionadas que apresentaram fotografias das personagens entrevistadas continham as figuras de mães nos contornos domésticos e nos modos de significação da precariedade. A aparição dessas mulheres na cena jornalística traça os sentidos sociais da ocupação dos espaços doméstico e escolar, bem como aponta para as problemáticas relacionadas a gênero, representatividade midiática e relações socioeconômicas, as quais foram silenciadas dentro das abordagens que se voltam para o ensino remoto emergencial.

A reportagem "As histórias de quem tenta salvar o ano perdido da educação" traz uma condução diferente da narrativa fotográfica se comparada às outras matérias apresentadas por $O$ Globo. As imagens que retratam as personagens entrevistadas são amplas nas dimensões da tela, em formato panorâmico, e trazem alguns elementos 


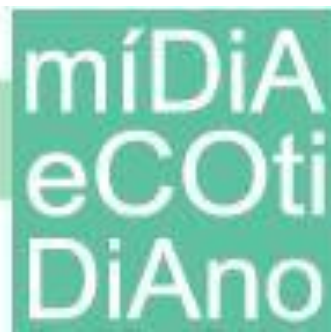

compositivos da informação que destacam outros vieses para as problemáticas do ensino remoto: a aluna sentada do lado de fora de sua casa, inserida no contexto da comunidade; a mãe com seu filho na rua da vila em que moram; um professor em situação de gravação das aulas; uma família que recorreu ao ensino particular para conduzir a educação dos filhos na quarentena; um garoto com deficiência que brinca sozinho no playgound. As fotografias mobilizam situações de precariedades diversas que não as da falta do ensino remoto, mas as da falta da socialização e das dinâmicas de aprendizagem no ensino presencial. Nessa reportagem, o jornal aborda situações de diversidade dentro das temáticas da evasão escolar e da situação econômica de donos de creches.

Figura 8 - Fotografia da reportagem "As histórias de quem tenta salvar o ano perdido da educação" de 20/09/20

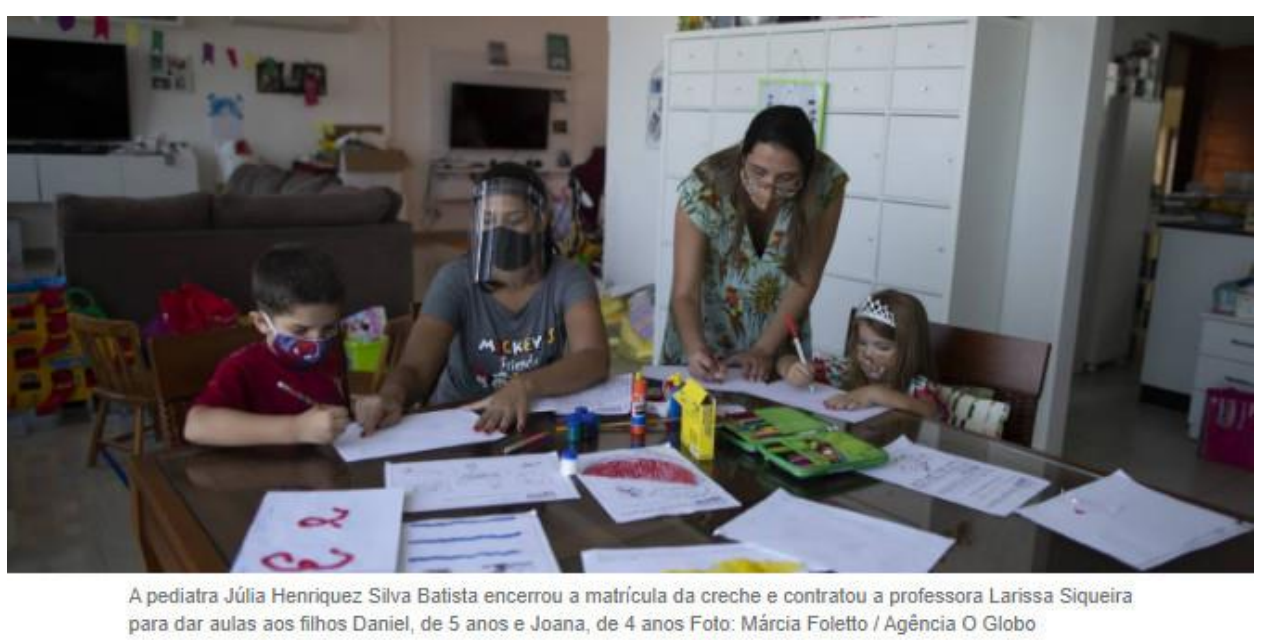

Fonte: Reprodução.

Outro ponto importante da construção dos noticiários pesquisados é o papel das relações entre as fotografias e os textos, principalmente os que acompanham as imagens nos quadros visuais das páginas, como os títulos e as legendas. Conforme Sousa (2002), o tecido narrativo do jornalismo integra essas duas dimensões - imagem e texto -, no sentido de relevância, orientação de sentidos e/ou interpretação de conteúdo. Os títulos e as legendas são essenciais às correspondências e às ancoragens no jornalismo, o que fica evidente ao observarmos o papel do texto na construção da significação do acontecimento, dos discursos sobre a experiência do ensino remoto ou das situações de 


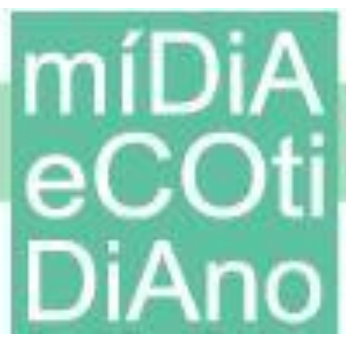

carências. Nos casos estudados, os textos direcionam os sentidos das fotografias de forma a agregar as idades e profissões de personagens, as comunidades em que moram, escolaridade, entre outras informações complementares que compõem a leitura extraquadro e que fazem a multiplicação de referentes. Pode-se ancorar, denotar, reorientar ou complementar a informação imagética (SOUSA, 2002, p. 76).

\section{Considerações finais}

Acreditamos que as narrativas visuais produzidas pelos dois jornais tradicionais - Folha de S.Paulo e $O$ Globo - sobre as carências relacionadas ao ensino remoto no Brasil são relevantes demonstrações de sistemas simbólicos mobilizados para as representações da alteridade, considerando, sobretudo, a circulação das notícias que se dá no ambiente midiatizado e o que se concretiza enquanto esfera coletiva. As reportagens levantam compreensões sobre a precariedade, os desafios educacionais de moradores das periferias brasileiras, da mesma forma que trabalham com estereótipos nos discursos identitários e convocam normatizações para falar dos sujeitos em situações de carência de estudo durante a pandemia. Percebemos as rotinas do fazer jornalístico, assim como uma estética que visa atender à velocidade das mídias digitais e às feições de um jornalismo móvel e hipertextual.

Ao lado de muitas imagens de precariedade estão as de alunos de escolas particulares que recebem materiais e acessam as aulas online. Ambos jornais construíram muitas notícias ancoradas em relações de dualidade, utilizando-se de comparações. Vale destacar as distinções entre a condução do ensino nas escolas particulares e nas escolas públicas. Muitas significações podem ser observadas ao direcionamos nossos olhares para os capitais simbólicos em jogo, sobretudo no lugar ocupado pelo campo educacional nas conduções do fazer jornalístico: as imagens públicas, as autoridades e as abordagens que dizem sobre o direito à educação, bem como tudo isso reverbera no tecido social.

O espaço ocupado pela educação nas relações de poder dentro de uma sociedade midiatizada passa em grande medida pela cobertura jornalística efetivada nas redes digitais, notícias em circulação pelos espaços ampliados da tecnocultura. Por esse motivo, as abordagens sobre o fato social e como esse é colocado como tema relevante, sobretudo 


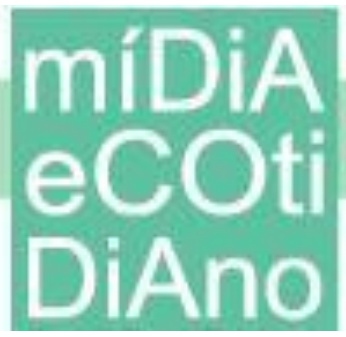

como pauta fotográfica no jornalismo online, tornam-se componentes essenciais das relações entre o campo jornalístico e os demais campos sociais, como o educacional.

Percebemos ainda como o jornalismo para os meios digitais configura uma dimensão relevante sobre esse "outro" analisado neste artigo. Os sujeitos inscritos nos discursos da alteridade são aqueles que não conseguem ter acesso aos jornais tradicionais, seja no impresso ou digital, via assinaturas. O conteúdo gratuito em circulação pelas redes sociais e comunidades virtuais - ou parte do conteúdo - é o que pode chegar a essas pessoas representadas nas reportagens. Assim, a imprensa tradicional apresenta-se como o lugar do discurso da identidade, reafirmando sua hegemonia social e econômica, enquanto esses sujeitos são retratados em condição de alteridade, por mais que a realidade das periferias seja a mais representativa da sociedade brasileira.

A criação de identidades estereotipadas por meio das fotografias, passando as ideias da precariedade e das assimetrias, está amplamente relacionada com as questões que envolvem mídia, representações sociais e pertencimentos. As coberturas sobre a educação nos direcionam a pergunta se a imprensa traz, por meio das fotografias e dos olhares das pessoas retratadas, a condução de lutas sociais existentes. Também nos levam a refletir de que modos os sujeitos podem ser evidenciados nos lugares de protagonismo, resistência e luta nessas fotografias, voltando-nos para o pensamento apresentado por Kellner (2001) de que os componentes culturais da identidade estão nas representações de resistências, numa abordagem multicultural crítica.

\section{Referências}

ALSINA, Miguel Rodrigo. A construção da notícia. Petrópolis: Vozes, 2009.

BARDIN, Laurence. Análise de conteúdo. Lisboa: Edições 70, 2008.

BERGER, Peter; LUCKMANN, Thomas. A construção social da realidade. Tratado de Sociologia do Conhecimento. 27 ed. Petrópolis: Vozes, 2007.

BOURDIEU, P. O poder simbólico. Rio de Janeiro: Bertrand Brasil, 1989.

BRAGA, J. L. Circuitos versus campos sociais. IN: JANOTTI JR, Jeder; MATTOS, Maria Ângela e JACKS, Nilda (orgs.). Mediação \& Midiatização. Salvador/Brasília: EDUFBA/Compós, 2012. p. 31-52. Disponível em: http://www1.pucminas.br/imagedb/documento/DOC_DSC_NOME_ARQUI201802051113 02.pdf. Acesso em: 22 jul. 2020. 
BUITONI, Dulcília. Fotografia e jornalismo: a informação pela imagem. São Paulo: Saraiva, 2011.

CANCLINI, Néstor García. Consumidores e cidadãos: conflitos multiculturais da globalização. Rio de Janeiro: Editora UFRJ, 1999.

GOMES, Mayra Rodrigues. Comunicação e identificação: ressonâncias no jornalismo. Cotia, SP: Ateliê Editorial, 2008.

HJARVARD, Stig. Midiatização: conceituando a mudança social e cultural. São Paulo:

Matrizes. Revista do Programa de Pós-Graduação em Ciências da Comunicação da USP. v. 5, n. 2, jan-jun 2012, pp. 53-91. Disponível em: https://www.redalyc.org/pdf/1430/143023787004.pdf. Acesso em: 24 jul. 2019.

KELLNER, Douglas. A cultura da mídia. Estudos culturais: identidade e política entre o moderno e o pós-moderno. Bauru, SP: EDUSC, 2001.

KOSSOY, Boris. Realidades e ficções na trama fotográfica. 4. ed. São Paulo: Ateliê Editorial, 2009.

MACHADO, Arlindo. A ilusão especular: introdução à fotografia. São Paulo: Brasiliense, 1984.

MARTÍN-BARBERO, Jesús. Tecnicidades, identidades, alteridades: mudanças e opacidades da comunicação no novo século. In: MORAES, Dênis de (org.). Sociedade Midiatizada. Rio de Janeiro: Mauad, 2006.

MONTEIRO, E. B. Fotojornalismo brasileiro e a crise das representações na sociedade pósindustrial. Comunicação \& Informação, v. 3, n. 1, p. 40-55, 2000. Disponível em: https://www.revistas.ufg.br/ci/article/view/22861. Acesso em: 4 nov. 2020.

MUNHOZ, Paulo. Estágios de desenvolvimento do fotojornalismo na internet. Diálogos \& Ciência: Revista da Rede de Ensino FTC. Ano V, n. 11, set. 2007.

ROUILLÉ, André. A fotografia: entre documento e arte contemporânea. São Paulo: Senac, 2009.

SILVA, Fernando Firmino da. Jornalismo móvel. Salvador : EDUFBA, 2015.

SILVA, Tomaz Tadeu da. A produção social da identidade e da diferença. In: SILVA, Tomaz Tadeu da (org). Identidade e diferença. A perspectiva dos estudos culturais. Petrópolis: Vozes, 2000 .

SODRÉ, Muniz. Antropológica do espelho: uma teoria da comunicação linear e em rede. Petrópolis, RJ: Vozes, 2008.

SOUSA, Jorge Pedro. Fotojornalismo: uma introdução à história, às técnicas e à linguagem da fotografia na imprensa. Porto, 2002. Disponível em: http://www.bocc.ubi.pt/pag/sousa-jorgepedro-fotojornalismo.pdf. Acesso em: 5 ago. 2019. 


\begin{abstract}
Anexo
Notícias e reportagens, com cobertura fotográfica, que abordaram as problemáticas da precariedade e da falta de acesso à educação remota
\end{abstract}

FOLHA DE S.PAULO (www.folha.uol.com.br/ @fohadespaulo)

Na periferia de SP, mães tentam driblar falta de material para ensino a distância https://fotografia.folha.uol.com.br/galerias/1662972015859008-na-periferia-de-sp-maes-tentamdriblar-falta-de-material-para-ensino-a-distancia

Galeria de fotos também presente na seguinte reportagem: Coronavírus terá efeito colateral de ampliar desigualdade na educação: https://www1.folha.uol.com.br/educacao/2020/06/coronavirus-tera-efeito-colateralde-ampliar-desigualdade-na-educacao.shtml

Ensino a distância em SP começa com dúvidas de pais e alunos https://fotografia.folha.uol.com.br/galerias/1665175978317772-ensino-a-distancia-em-spcomeca-com-duvidas-de-pais-e-alunos

Aulas à distância durante a pandemia expõem desigualdades na educação https://fotografia.folha.uol.com.br/galerias/1666156786426290-aulas-a-distancia-durante-apandemia-expoem-desigualdades-na-educacao

Galeria de fotos também presente nas seguintes reportagens:

Cursinho aposta em sala virtual e 800 horas de aula grátis para preparação do Enem: https://www1.folha.uol.com.br/educacao/2020/07/cursinho-aposta-em-sala-virtuale-800-horas-de-aula-gratis-para-preparacao-do-enem.shtml?origin=folha

Sindicato contesta declarações de secretário da Educação de SP à Folha: https://www1.folha.uol.com.br/educacao/2020/06/sindicato-contesta-declaracoesde-secretario-da-educacao-de-sp-a-folha.shtml

No Ceará, aluno espera mãe chegar em casa para estudar com celular: https://www1.folha.uol.com.br/educacao/2020/07/no-ceara-aluno-espera-maechegar-em-casa-pra-estudar-com-celular.shtml

Coronavírus terá efeito colateral de ampliar desigualdade na educação: https://www1.folha.uol.com.br/educacao/2020/06/coronavirus-tera-efeito-colateralde-ampliar-desigualdade-na-educacao.shtml

Interrupção das aulas na pandemia pode reduzir PIB brasileiro em até 23\%: https://www1.folha.uol.com.br/educacao/2020/06/interrupcao-das-aulas-na-

pandemia-pode-reduzir-pib-brasileiro-em-ate-23.shtml

Governo Bolsonaro vai apostar em game finlandês de alfabetização: https://www1.folha.uol.com.br/educacao/2020/11/governo-bolsonaro-vai-apostarem-game-finlandes-de-alfabetizacao .shtml?origin=folha

Para forçar volta à escola, MEC resiste em homologar permissão de aula remota até fim de 2021: https://www1.folha.uol.com.br/educacao/2020/11/para-forcar-volta-aescola-mec-resiste-em-homologar-permissao-de-aula-remota-ate-fim-de-

2021.shtml?origin=folha 
Alunos da escola pública de SP têm problemas no ensino a distância

https://fotografia.folha.uol.com.br/galerias/1675234347213446-alunos-da-escola-publica-de-sptem-problemas-no-ensino-a-distancia

\section{O GLOBO (https://oglobo.globo.com / @ jornaloglobo)}

Sem estrutura em casa, estudantes lutam para se preparar para o Enem 2020

https://oglobo.globo.com/sociedade/educacao/enem-e-vestibular/sem-estrutura-em-casaestudantes-lutam-para-se-preparar-para-enem-2020-24428125

'Há crianças passando fome': Estados e prefeituras deixam sete milhões sem merenda https://oglobo.globo.com/sociedade/educacao/ha-criancas-passando-fome-estados-prefeiturasdeixam-sete-milhoes-sem-merenda-24430857

Estudantes de pelo menos 10 estados deixaram de receber alimentação escolar https://oglobo.globo.com/sociedade/educacao/estudantes-de-pelo-menos-10-estados-deixaramde-receber-alimentacao-escolar-1-24430856

Escolas precisam de álcool em gel contra Covid-19, mas 10 mil das públicas não têm nem água limpa

https://oglobo.globo.com/sociedade/582327-escolas-precisam-de-alcool-em-gel-mas-10-milcolegios-publicos-nao-tem-nem-agua-limpa

Censo Escolar mostra que escolas públicas não têm equipamentos, nem práticas de educação digital

https://oglobo.globo.com/sociedade/educacao/censo-escolar-mostra-que-escolas-publicas-naotem-equipamentos-nem-praticas-de-educacao-digital-24515637

Enem: Entenda como novas datas podem aprofundar desigualdades educacionais https://oglobo.globo.com/sociedade/enem-entenda-como-novas-datas-podem-aprofundardesigualdades-educacionais-24522587

As histórias de quem tenta salvar o ano perdido da educação https://oglobo.globo.com/sociedade/educacao/as-historias-de-quem-tenta-salvar-ano-perdidoda-educacao-24649202

Pandemia: 7,6 milhões de estudantes não tiveram aula em agosto, aponta IBGE https://oglobo.globo.com/sociedade/educacao/pandemia-76-milhoes-de-estudantes-nao-tiveramaula-em-agosto-aponta-ibge-24655387

Primeiras avaliações de ensino na pandemia, feitas na EJA, mostram falta de critérios e aprovações automáticas

https://oglobo.globo.com/sociedade/educacao/2275-primeiras-avaliacoes-de-ensino-napandemia-feitas-na-eja-mostram-falta-de-criterios-aprovacoes-automaticas-24678375

'Não Desista do seu Futuro': projeto busca conter evasão escolar no Brasil pós-pandemia https://oglobo.globo.com/sociedade/educacao/nao-desista-do-seu-futuro-projeto-busca-conterevasao-escolar-no-brasil-pos-pandemia-24688274 
Tempo na pandemia de estudo de adolescentes das classes mais altas é $64 \%$ maior do que dos pobres

https://oglobo.globo.com/sociedade/educacao/tempo-na-pandemia-de-estudo-de-adolescentesdas-classes-mais-altas-64-maior-do-que-dos-pobres-24703054

Busca por emprego tira mais jovens das aulas remotas do que falta de internet, diz pesquisa https://oglobo.globo.com/sociedade/582327-busca-por-emprego-tira-mais-jovens-das-aulasremotas-do-que-falta-de-internet-diz-pesquisa-24729442

Maioria dos alunos que moram em favelas no país ficou sem estudar na pandemia https://oglobo.globo.com/sociedade/educacao/maioria-dos-alunos-que-moram-em-favelas-nopais-ficou-sem-estudar-na-pandemia-24734437. 